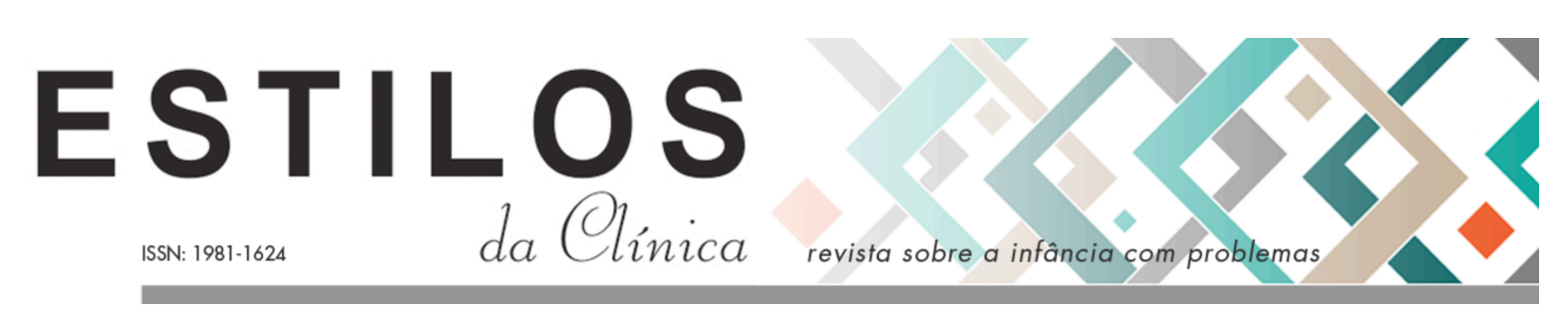

DOI: https://doi.org/10.11606/issn.1981-1624.v26i1 p29-43.

\title{
Dossiê
}

\section{Orientação educacional com psicanálise: um lugar de escuta em tempos de escola remota}

\author{
Iris Ramos Lacava Ferraz
}

Resumo. O presente artigo traz, a partir da análise das falas dos atendimentos realizados pela orientação educacional no período de ensino remoto, efeitos e reflexões que um espaço de escuta pode produzir durante a pandemia de COVID-19. De modo virtual, a busca pelo Serviço de Orientação Educacional seguiu acontecendo, e trouxe pontos que nos são caros para pensar a parentalidade na atualidade. À luz da psicanálise, discute-se dois apontamentos a partir dos atendimentos realizados: o primeiro localiza-se justamente na demanda que é levada à escola, sinalizando um apelo ao saber sobre a criança à quem supõe-se saber sobre toda criança. O segundo diz respeito ao discurso dos pais sobre o filho - que revela algo para além daquilo que se apresenta.

Palavras chave: psicanálise; orientação educacional; ensino remoto; escuta; parentalidade.

\section{Orientación educativa con psicoanálisis: un lugar de escucha en tiempos de escuela remota}

Resumen. Este artículo trae, a partir del análisis discursivo de la asistencia prestada por la orientación educativa en el período de la educación a distancia, los efectos y reflexiones que pueden producir un espacio de escucha durante la pandemia de COVID-19. De manera virtual, la búsqueda del Servicio de Orientación Educativa continuó y trajo puntos que nos son valiosos para pensar en la paternidad hoy en día. A la luz del psicoanálisis, se discuten dos apuntes en función de los servicios prestados: el primero se encuentra precisamente en la demanda que se lleva a la escuela, señalando una apelación para saber sobre el niño de aquel que debe supuestamente saber sobre todos los niños. El segundo se refiere al discurso de los padres sobre el niño, que revela algo más allá de lo que se presenta.

Palabras clave: orientación educativa; psicoanálisis; educación a distancia; paternidad; escucha.

\section{Educational guidance with psychoanalysis: a place of listening in times of remote school}

Abstract. This present article brings trough the discursive analysis of the services provide from the educational guidance in the remote teaching period, effects and reflections that a listening space can provide during the COVID-19 pandemic. In a virtual mode, the search for the Educational Guidence Service kept happening and brought up valuable points to us to think about parenthood these days. In the light of psychoanalyses it is discussed

\footnotetext{
* Orientadora educacional. Mestre em Teoria Psicanalítica pela Universidade Federal do Rio de Janeiro, Rio de Janeiro, RJ, Brasil. Email: irislacava@gmail.com
} 
two different notes from the services provided: the first one is precisely located on the demand that is taken to school, signaling an appeal to know about the child from whom it is supposed to know about every child. The second one is about the parents' speech about the child, that reveals somenthing beyond that what is presented.

Keywords: educacional-guidance; pschoanalyses; remote learning; parenthood; listening.

\section{Orientation pédagogique avec la psychanalyse: un lieu d'écoute en période d'école éloignée}

Résumé. Ce présent article apporte, à partir de l'analyse discursive de l'assistance fournie par l' orientation pédagogique dans la période d'enseignement à distance, des effets et des réflexions qu'un espace d'écoute peut produire pendant la pandémie COVID-19. Dans un mode virtuel, la recherche du Service d'orientation pédagogique en a continué et a soulevé des points qui nous sont chers pour réfléchir à la parentalité aujourd'hui. À la lumière de la psychanalyse, il est discuté deux notes différentes des services fournis: la première est précisément située sur la demande qui est emmenée à l'école, signalant un appel au savoir sur l'enfant à qui on suppose savoir à propos de chaque enfant. Le second concerne le discours des parents sur l'enfant - qui révèle quelque chose au-delà de ce qui est présenté.

Mots-clés: orientation éducative; pschoanalyses; enseignement à distance; parentalité; écoute.

\footnotetext{
A pandemia de COVID-19 impôs a muitos - escola, criança e pais - o convívio cotidiano do confinamento; para muitas crianças, em especial, foram meses de estar longe do espaço escolar, impostos por decretos oficiais do Estado. Neste ínterim, pudemos notar a crescente oferta de lives e cursos online sobre como lidar com tal contingência; sabemos, porém, que cada um experienciou esse momento histórico à sua maneira.

Essa transposição repentina e inesperada da escola para o ambiente virtual não trouxe mudanças apenas na rotina de todos os envolvidos; o fato de a escola ter saído de cena como um lugar terceiro na relação entre pais e filhos foi também revelador de questões do âmbito dessa relação privada. Pelas telas dos dispositivos eletrônicos, a sala de aula passou a ser dentro de casa. Com isso, a busca pelo Serviço de Orientação Educacional seguiu acontecendo e, embora motivada por questões aparentemente similares, aponta para algo que se revela estar além da queixa apresentada: o mal-estar, impossível e incontornável, que atravessa a todos no recorte aqui proposto -: a relação parental. Tais questões apontam, por um lado, o quão revela-dor é o (des)encontro do adulto frente à criança; e desvelam, por outro lado, pontos que nos são caros para pensar a parentalidade nos tempos de hoje.

O presente artigo traz, a partir de recortes de falas dos atendimentos realizados ao longo do período de ensino remoto, efeitos que um espaço de escuta no ambiente virtual pode produzir durante a pandemia. Desvela, ainda, um deslizamento do que inicialmente se apresentava como queixa; dessa forma, foi possível tocar em pontos que anunciam algumas questões. Dar lugar à palavra e permitir o aparecimento de significantes revela-se, ainda que por vias remotas, produtor de novos sentidos na experiência de parentalidade, num mais além do discurso queixoso sobre a criança.

Ao tomar os esquemas narrativos dos pais sobre os filhos direcionados à instituição escolar no período em que esta se esteve vivenciada de dentro de casa, apontamos duas reflexões possíveis: a primeira localiza-se justamente na demanda que é levada à escola, sinalizando um pedido, um apelo ao saber sobre a criança à quem supõe-se saber sobre toda criança. A segunda
} 
reflexão diz respeito ao discurso dos pais sobre o filho - o que, muitas vezes, revela algo para além daquilo que se diz e da própria demanda apresentada à escola.

O primeiro apontamento que levantamos é que o adulto parental, frente ao seu filho, dirigese à escola buscando orientação, em primeiro momento, como se tratasse da criança de forma genérica. Não é neste vetor, no entanto, que caminhamos, já que o trabalho do orientador educacional com a psicanálise está em operar no intervalo entre aquilo que aparece como queixa e a mobilização que o desvelamento de questões produz naquele adulto frente àquela criança. Buscamos, afinal, produzir efeitos a partir do que possa ser dito da criança em questão, do que se constitui na relação parental daquela família, trazendo à tona questões da especificidade do caso atendido.

Já o segundo ponto levantado, nos remete à questão sintomática da/na criança, que, muitas vezes, usa dos sintomas para falar; estes, de alguma forma, herdados dos próprios pais. Este ponto nos ajuda a pensar, ainda, sobre a experiência parental e o atravessamento do mal-estar na atualidade.

Dolto (2005) afirma que são três os motivos pelos quais "a causa das crianças é muito mal defendida no mundo" (Dolto, 2005, p. 5): o primeiro traz o discurso científico, "cada vez mais abundante no assunto (...) oculta a realidade simbólica, a potência específica, a energia potencial presente em cada criança. (...) a criança torna-se objeto de estudo para o pesquisador em medicina e em ciências humanas." (Dolto, 2005, p. 5). O segundo aponta a sociedade, que "preocupa-se em $1^{\circ}$ lugar em rentabilizar o custo das crianças" (Dolto, idem). E, finalmente, o $3^{\circ}$ e último motivo, é o fato de que "os adultos têm medo de liberar certas forças, certas energias das quais as crianças são portadoras e que questionam sua autoridade, suas aquisições e suas posições sociais. Eles projetam na criança seus desejos contrariados e seu mal-estar, impondolhes seus próprios modelos" (Dolto, ibidem).

A captura do discurso científico sobre a criança traz expectativas sociais, frutos do imaginário social sobre a criança; está relacionada à busca pelo saber sobre esta de forma genérica, como se houvesse uma receita possível que fosse capaz de esgotar a queixa apresentada a partir de um saber fazer específico.

Já o terceiro motivo do qual Dolto (2005) se refere, abarca questões mais contundentes da relação pais e filhos, fazendo emergir pontos como: os desafios da experiência parental; as tensões provenientes do mal-estar que atravessa as relações parentais; a manutenção dos sintomas que se fazem nessa relação.

Esses mesmos dois motivos apontados por Dolto (2005) fazem relação aos dois apontamentos levantados anteriormente: o primeiro faz menção ao discurso social sobre a criança, e dos efeitos que isso produz na relação genérica entre o adulto e a criança; e o segundo, que inclui a psicanálise, convida-nos a pensar sobre a relação parental. É a partir daí que faremos nossas reflexões junto aos recortes do discurso dos pais que chegaram à orientação educacional durante a pandemia.

Em princípio, faremos um recorte do que apresentamos como o exercício da orientação educacional que inclua a psicanálise. Tendo a psicanálise como lugar de interrogação da experiência do sujeito em cultura, e o ofício do orientador educacional como um lugar de acolhimento, acompanhamento e reflexão da experiência escolar do aluno, é que propomos o termo orientação educacional com a psicanálise. Com isso, visamos a sustentação de uma posição ética do trabalho educativo que inclui em sua cena o sujeito do inconsciente; apostamos na circulação da palavra para promover a ressignificação dos lugares subjetivos de cada um no espaço escolar. 
Ainda nessa parte do artigo, trataremos de relacionar as expectativas do imaginário social, do que se apresenta como discurso científico sobre a criança no campo da educação na atualidade com a implementação da Base Nacional Curricular Comum - em especial quanto ao ensino das chamadas competências socioemocionais. Consideramos, afinal, que isso pode estar relacionado com a prevalência de um discurso que se proponha pleno de saber, e de sua tentativa de apagamento do sujeito.

Em seguida analisaremos recortes discursivos de atendimentos a pais de alunos das séries iniciais do Ensino Fundamental da rede privada realizados de forma remota, de onde apontaremos algumas reflexões relativas às seguintes questões: 1) se a escola é a instituição de educação formal destinada à toda criança, que saber sobre a criança é esperado encontrar ali atualmente? Dito de outro modo, que tipo de saber busca o adulto que leva à instituição escolar as queixas sobre uma criança? 2) Se tomarmos a queixa como um sinal de algo a mais da relação parental, quais são os efeitos e reflexões que a escuta desta queixa de um pai ou mãe sobre seu filho(a) podem produzir em tempos de ensino remoto?

\section{A orientação educacional com a psicanálise}

Embora essa função tenha sido excluída quanto a obrigatoriedade nas escolas em 1996, existem instituições escolares que mantém no seu quadro de equipe pedagógica o orientador educacional. O papel deste educador costuma ser o de acompanhar o aluno ao longo da sua escolarização - atento às questões pedagógicas, mas também subjetivas, sociais e familiares. De modo geral, o SOE (Serviço de Orientação Educacional) é responsável por estabelecer a ligação entre todos aqueles diretamente envolvidos na escola - os alunos, os professores, as famílias e a sociedade. Para tanto, tem como importante ferramenta de trabalho a circulação da palavra.

De acordo com Grinspun (2011), o orientador educacional no Brasil visa "trabalhar com o aluno como um sujeito histórico, crítico e social", de modo a transcender o papel deste educador para além dos muros da escola e do mercado de trabalho (Grinspun, 2011, p. 31). Diferente de limitar-se à educação formal/acadêmica, o orientador educacional opera a favor do aspecto formativo dos alunos, considerando, para tanto, sua constituição subjetiva e sua historicidade. Desta forma, tomando o aluno/professor/familiar parental como sujeito, consideramos a pertinência de algum enlace entre a orientação educacional e a psicanálise.

Nossa proposição de um Serviço de Orientação Educacional que inclua a psicanálise também sustenta-se na premissa de que todo educador norteia-se por objetivos educativos ideais. Sabemos, em contrapartida, que o ato educativo nos coloca diariamente de frente com o impossível, onde confrontamos o fracasso das práticas educativas, onde nos deparamos com o real - o que pode potencializar nossas angústias frente àquilo que não se cumpre com tais ideais.

Tendo exposto esses pontos, buscamos na teoria psicanalítica uma via de inflexão, que possibilite ao orientador educacional abrir caminhos, mobilizar novas perguntas, e que se pense outras formas de encaminhamentos para os casos fracassados que acompanhar ao longo do seu ofício.

O orientador educacional municiado pela psicanálise está na escola para identificar, acolher e apontar caminhos para os problemas emergentes das relações entre a instituição e os alunos, entre os professores e os alunos, entre as famílias e a instituição, e, ainda, para as questões que, embora vividas no âmbito privado, entre família e aluno, possam produzir efeitos no ambiente 
escolar. Enfim, cabe ao orientador educacional propor encaminhamentos aos impasses provenientes dessas relações. É, afinal, um profissional da educação que atua a partir dos efeitos do mal-estar, ultrapassando, assim, o investimento na educação formal/acadêmica. Em suma: um ofício impossível cujas demandas de trabalho são tão evidentes quanto inesgotáveis.

Algo que aproxima o trabalho do orientador educacional em relação ao trabalho do analista é a escuta. Sabemos que tanto no ato falho quanto no sintoma ou no sonho o sujeito aparece; as formações do inconsciente constituem-se numa estrutura linguageira, tendo como um exemplo a forma de uma produção metafórica: pela substituição de um significante por outro, tem-se a possibilidade interpretativa do analista. Ao orientador educacional não cabe a função de interpretar o que do sujeito possa aparecer, mas sim devolver-lhe os significantes, oferecendo possibilidades dele próprio fazer suas interpretações; num movimento de convocar ao passo que se propõe, em alguma instância, ao sujeito, um trabalho psíquico que é dele.

Diferente do analista - que parte do plano das demandas de quem busca uma psicanálise, visando um percurso subjetivo rumo ao desejo -, o orientador educacional fica apenas no primeiro plano, recebendo e sendo convocado a dar encaminhamento, alguma resposta, às diferentes demandas que se apresentam na escola por parte dos sujeitos com que trabalha. Propomos, assim, que o orientador educacional com a psicanálise possa, não apenas encaminhar respostas frente às queixas que se apresentam, mas fazer perguntas, proporcionar ao sujeito um movimento de se reconhecer e se implicar na questão que se apresenta na sua fala.

A partir da queixa sobre um aluno que esteja enfrentando uma questão relativa ao universo escolar, há um percurso de estudo de caso a ser feito. E cabe ao orientador educacional trabalhar / operar em cima daquela queixa, bem como levantar hipóteses sobre o sintoma da criança na escola, no intuito de propor um encaminhamento de tais questões. Em alguma medida, há que se romper com o discurso normativo sobre a criança, e abrir espaço para o discurso sobre aquela criança.

Para além da perspectiva desenvolvimentista, consideramos a constituição do sujeito; para além do organismo, admitimos um corpo pulsional. Mais do que vislumbrar um ideal de sucesso, propomo-nos defrontar com o real presente no fracasso de uma investida educativa. Nossa aposta, afinal, é que a psicanálise opere no campo educacional de modo a dar lugar para o sujeito, por meio da escuta. E, com isso que traz na fala o sujeito, abrir caminhos de saber que não estão prontos ou dados de saída, mas que se fazem à medida em que as questões se apresentam em palavras. Para tanto, a psicanálise nos ajuda no sentido de que é condição sine qua non tratar cada caso como se fosse o primeiro.

Diferente de pensar numa pedagogia psicanalítica, algo que não existe de fato, Voltolini argumenta que "a posição da psicanálise no campo educativo é a de desmontar a pedagogia enquanto discurso mestre exclusivo sobre a educação" (Voltolini, 2011, p.10). Isso também nos permite dizer, com Voltolini (2011), que a psicanálise frente à educação,

\footnotetext{
Nos fala, antes, sobre a precariedade inevitável de todo ato educativo, sobre a ignorância particular e insuperável, embora não incontornável, de todo adulto em relação à criança e sobre o campo amoroso que se instala entre o educador e o educando, permeando essa relação com uma atmosfera particular, decisiva quanto ao destino da aprendizagem. Fala também sobre o incerto caminho do sujeito ao longo de sua educação e dos riscos de naufrágio nessa viagem. (Voltolini, 2011, p.11)
}

É comum ouvir que a criança é o futuro da nação. Arendt (apud Santiago, 2015) afirma que a criança é a emergência do novo a partir da sua representação do presente; com isso, a criança tende a ser vista a partir de uma perspectiva que lhe imprime marcas culturais carregadas de 
utopias específicas. À medida em que incorporam inovações de sua contemporaneidade, também produzem angústia e inquietações aos adultos dessa mesma atualidade. A partir desta questão, Santiago (2015) observa que

\begin{abstract}
é por meio desse fenômeno de identificação com o tempo presente que, na percepção dos adultos, as ameaças contemporâneas vão integrar a personalidade de crianças e adolescentes. Para os mais velhos, as novas gerações são sempre ameaçadoras, pois 'do ponto de vista dos mais novos, o que quer que o mundo adulto possa propor de novo é necessariamente mais velho do que eles mesmos'. (Santiago, 2015, p. 21)
\end{abstract}

Salientamos, ainda, a posição social da infância da atualidade - seja no âmbito jurídico que a cerceia em leis, seja pelo discurso científico que busca imprimir leis de desenvolvimento e aprendizagem baseadas em premissas comportamentalistas, seja pelo interesse do mercado que a tomam como forte consumidor - o que resulta à criança um lugar público na sociedade em contraposição ao lugar do adulto na atualidade que, "diante da criança pública, caracterizada por seus direitos, encontra-se o adulto privado, caracterizado por seus deveres" (Voltolini, 2016, p. 8). Segundo o autor, a criança da atualidade estaria sendo convocada a sair do seu lugar de infans, daquele "que não tem o direito de falar" (idem, p.7) sendo demandada à ocupar um lugar público; enquanto o adulto, por outro lado, passa a ocupar o lugar de "privação da coisa pública" (idem, p.8). Em alguma medida,

o esquadrinhamento da criança pública gerou como efeito colateral a criação de um superego educativo para adultos. Infantilizados pela obediência regulamentada a preceitos, seja como pais desnorteados em busca de uma super-Nany de plantão, ou como professores convocados a se formar eternamente nos cursos que visam a sua melhor adaptação à criança pública (Voltolini, 2016, p.8)

Somado a isso, parece haver uma dificuldade do adulto em lidar com o infantil da criança, como se isso dissesse respeito a algo desconhecido e ameaçador. $\mathrm{O}$ efeito, pelas nossas observações, é o da não escuta dessas crianças; mais do que isso, além de não serem ouvidas, as crianças são apenas faladas a partir de uma suposição construída pela fantasia do adulto / educador. Em geral, é isso que norteia o saber sobre a criança numa escola. Isso ficou evidente quando, nos atendimentos realizados ao longo da pandemia - momento em que as crianças estavam com os pais em casa - a procura pela escola antecedeu qualquer escuta desses pais à própria criança em questão. A criança, na sua singularidade, aparece pela fala dos pais, a partir da sua leitura sobre a criança; antes disso, no entanto, o que houve foi a busca por um saber especialista sobre a criança na sua forma genérica. Dito isso, salientamos a importância de proporcionar a escuta, também a fim de minimizar os efeitos fantasmagóricos desse (des)encontro entre adulto/pai-mãe e criança/filho.

Pensar o que se espera da educação faz-se necessário para que se possa, justamente, identificar as suas demandas. Isso nos leva ao contexto atual da educação e das expectativas em torno de um certo ideal - como se existisse uma forma exata de responder ao fracasso das investidas educativas.

Para refletir acerca dos discursos vigentes, sobre o que se espera encontrar como saber do especialista em educação, podemos tomar como exemplo os documentos normativos da educação brasileira, como a Base Nacional Curricular Comum - BNCC - e suas indicações de programas educativos, onde é explícita a demanda de trabalhar as chamadas competências socioemocionais nas escolas. De outra forma, vemos o reconhecimento do aluno para além do aspecto cognitivo; por outro lado, no entanto, preocupa-nos as indicações práticas que aparecem naqueles documentos e nos programas que se sugerem na implementação de tais normativas. 
Sabemos, com Freitas, et al (2018), que a publicação da versão vigente da BNCC contou com crescente participação (e pressão) dos grupos do terceiro setor, compostos por grandes empresas "vinculadas ao capital, tais como Fundação Lemann, Instituto Ayrton Senna, Fundação Roberto Marinho e outros" (Freitas, et al, 2018, p. 859). No texto final do documento, nomenclaturas referentes às finalidades da educação sofreram alterações junto com a Lei de Diretrizes e Bases, por força da Lei $\mathrm{n}^{\mathrm{o}} 13.415 / 2017$ - o que antes era nomeado direitos de aprendizagens, passam a remeter-se à ideia de competências (Freitas, ibidem).

A organização das áreas de conhecimento passou a ser nomeada como competências e habilidades. De acordo com a BNCC, o conceito de competência demarca as finalidades gerais do Ensino Fundamental e do Ensino Médio, e são definidas visando à mobilização de conhecimentos, habilidades, atitudes e valores a serem desenvolvidos pela escola.

Notamos que o significante competência, que vem substituir o termo direito de aprendizagem, provoca uma inversão na lógica: não mais a escola aparece como um espaço de oferecer ào aluno o direito de aprendizagem, mas agora o aluno é colocado em posição de cumprir a exigência de certas competências. Como efeito, essa lógica atual transfere para o indivíduo a responsabilidade do alcance dos ideais educativos, que têm na escola um espaço para que isso se dê.

Ao que parece, o discurso empregado junto às normativas e programas educativos oferecidos no Brasil na atualidade, imprimem a lógica (equivocada) do ensino de conduta e competência socioemocional pela via do eu consciente. Neste sentido, o aluno que aparece como objeto de trabalho não nos parece estar sendo considerado em sua lógica inconsciente. Na contramão do que consideramos importante para o ofício do educador, o discurso empregado a partir da implementação da BNCC e dos programas educacionais oferecidos pelos mesmos grupos do terceiro setor supracitados, apontam para a prevalência do sujeito da consciência, fazendo uma aposta na autonomia do eu - como se o humano fosse regido exclusivamente pela instância do $e u$, desarticulado do id e do superego. As novas terminologias e programas de práticas educativas buscam imprimir um ideal de simplicidade, como se para desenvolver uma competência emocional, bastasse ensinar sobre ela.

Existe, nesta lógica sugerida pelas normativas atuais, uma suposta autonomia do eu, que, desde seus primórdios, a psicanálise se ocupa de desconstruir, e a educação moderna, de construir.

Ao propormos o trabalho da orientação educacional com a psicanálise, estamos, de saída, assumindo posição de resistência ao viés adaptativo e psicologizante no exercício da educação. Vale salientar, contudo, que instrumentalizar-se da teoria psicanalítica não garante ao educador maior domínio sobre o processo educativo. O saber do inconsciente, o saber-fazer sobre o sintoma são produções que cabem à experiência analítica. Não compete ao orientador educacional aplicar o que se sabe sobre o inconsciente no contexto escolar - a psicanálise não é uma metodologia educativa.

O que defendemos é a admissão do sujeito do inconsciente na instituição escolar dando a ele a palavra, o saber. Apostamos, afinal, no atravessamento da psicanálise no ofício do educador com o objetivo de resistir às práticas psicologizantes na instituição escolar.

Com Freud (1925/1996), afirmamos que educar, psicanalisar e governar: ofícios impossíveis. A vida em cultura, que tem como principal aliada a educação, pode ser lida como um convite ao sujeito ao atravessamento de um impossível necessário. Educar e psicanalisar, servem ao sujeito no sentido de simbolizar a falta, a interdição do incesto. Um educador que se municie pela psicanálise, poderá despir o trabalho educativo de certos engodos imaginários, 
trazendo à cena educativa o real, o impossível de ser simbolizado. Sustentando inquietações e contrapondo-se à discursos e normativas que se propõem totalizantes no saber sobre a criança e o fazer educativo.

O humano é estruturado no campo da linguagem; isso, do mundo humano ser o mundo da linguagem, dá centralidade à palavra, tanto na experiência analítica quanto no processo educativo.

As contradições, alternações e substituições de significantes que compõem o jogo de fala entre os sujeitos no laço social, apontam para a evidência do sujeito. Não apenas o sujeito consciente, autônomo, racional; mas o sujeito do inconsciente, dotado de um saber construído em outra cena. Sobre isso, Lacan (2008) afirma: "desde que haja em algum lugar o sujeito suposto saber (...) há transferência" (Lacan, 2008, p. 226); ou seja, é na relação transferencial que se supõe um sujeito em processo de construção do saber, da sua verdade. Onde há um suposto sujeito, há um saber que nele se construiu.

Ter a psicanálise como ferramenta de trabalho da orientação educacional é, afinal, dar e sustentar um lugar ao sujeito do inconsciente, admitindo-o. Ao orientador educacional, atravessado pela psicanálise, cabe proporcionar o lugar de fala na escola. Diante da repetição de certos comportamentos, o que insiste em se apresentar como queixa, nos resta, antes de qualquer encaminhamento, apostar no lugar de fala, pois é pela palavra que o sujeito se evidencia, é pela palavra que as queixas se transformam em questões para além delas.

Considerando a contingência do mal-estar na parentalidade, incluindo como variável a experiência vivida ao longo da pandemia onde a escola "se mudou" para dentro de algumas casa, notamos a prevalência de queixas dos pais quanto às dificuldades das crianças cumprirem a rotina escolar. Isso, no entanto, revelou cenas que ultrapassam mesmo os muros da escola. Trazem pontos interessantes para pensarmos o discurso que é esperado sobre a educação $d a$ criança, bem como os impasses de se educar uma criança.

Numa lógica discursiva da atualidade de que haverá um lugar (a escola) onde especialistas (os educadores) darão orientações assertivas cujas respostas da criança deverão ser igualmente satisfatórias para tudo aquilo que envolve o trabalho de educar uma criança, nos leva à questão de se pensar o lugar da escola no imaginário atual: respostas prontas, práticas de conduta infalíveis, demanda por diagnósticos em laudos médicos. No seu ofício, o orientador educacional é questionado sobre o que e como fazer para melhor educar uma criança; criança essa, à princípio, apresentada de forma genérica. A forma como este educador vai responder à demanda do outro é, muitas vezes, o que determina o percurso educativo de cada criança - que, para nós importa na sua singularidade.

Dito isso, somos levados a refletir: o que vem a ser o sintoma na criança? Lacan (1998), em "Duas notas sobre a criança", ressalta pontos importantes da constituição do sujeito, de como isso está ligado à estruturação da criança em relação àqueles que, para ela, cumprem a função de Outro. Assim, o sintoma da criança aponta, muitas vezes, um sintoma da estrutura familiar; se este vem como representante da verdade - no caso do sintoma da criança -, isso seria o representante da verdade do casal familiar.

\section{Atendimentos online: da queixa à questão}

O objeto de reflexão aqui realizado tem alguns pontos em comum: partem dos recortes de falas de atendimentos realizados em encontros virtuais entre famílias e orientação educacional; 
os atendimentos foram solicitados por pais de crianças cursando as séries iniciais do Ensino Fundamental da rede particular, sob a queixa de resistência desta na sustentação da rotina escolar em casa. Tais famílias viveram, ao longo da pandemia, o confinamento para dentro de suas casas, e sem a escola como um lugar físico, passaram a se haver diariamente, com o acompanhamento da rotina escolar dos filhos; e, ainda, a defrontar-se com seu papel parental de modo mais direto e real.

Os pais de Anita ${ }^{1}$ buscaram a orientação educacional relatando a dificuldade dela em viver a rotina escolar em casa, pois a menina chora e se descontrola nos momentos de realização das tarefas; a mãe afirma que ela prefere ter o tempo livre, sem as obrigações escolares. Na sequência fala da sua própria falta de tempo disponível para a filha, visto que o trabalho, também migrado para o ambiente virtual, aumentou demasiadamente. Na fala da mãe, a falta de tempo livre para a filha veio na sequência do que reproduz ser a preferência da filha - que é de ter o tempo livre. A partir daí, relata, demonstrando culpa, que é comum estar estressada com o trabalho e acabar descontando na filha.

No espaço de fala aberto para os pais, após algumas perguntas e reflexões sobre o dia a dia deles neste novo contexto, a mãe conclui que o problema não está só na Anita: o espaço de escuta aberto para colocar a dinâmica da atual contingência daquela família, proporcionou aos pais um movimento de se incluírem na questão, onde se pode ver de outra perspectiva o contexto vivido neste momento. $\mathrm{O}$ que chegou como queixa sobre a criança e suas dificuldades, transforma-se numa questão que envolve toda uma dinâmica familiar - mais do que isso, todo um contexto.

Outro ponto que emergiu para os pais de Anita, foi o da falta de uma rotina minimamente previsível para a criança, pois faziam as atividades escolares apenas quando um dos pais tinha um tempinho livre ao longo do dia - podendo ser à noite ou aos finais de semana, inclusive. Novamente volta a questão do tempo livre, tão importante quando ter, para uma criança em idade escolar, o tempo de trabalho.

Curioso perceber que até mesmo para a organização de uma rotina dentro de casa, foi importante a atuação da orientação educacional durante o ensino remoto. Isso da relação com o tempo, notavelmente, foi uma perda na vida de muitas crianças em quarentena: muitos se viram à deriva da (in)disponibilidade dos pais dentro de casa. Corpo presente, presença ausente apareceu como marca dos atendimentos realizados nesse período. O que poderíamos, de saída, vislumbrar como um ganho, um tempo de reencontro dos pais com seus próprios filhos, podendo, enfim, assumir sua função educadora, parece ter retornado como sinal de culpa.

Incluir a criança, enquanto sujeito da própria rotina, também aparece como ponto de demanda efetiva dos pais que buscam os atendimentos. Engana-se quem acredita que a criança vá organizar-se sozinha no tempo e nos próprios afazeres, sem um mínimo de direcionamento, enquadre ou orientação do adulto. Falas como ele não faz nada sozinho são comuns; mas quando se questiona sobre o efetivo espaço de deixar que a criança construa seu fazer sozinha, é igualmente comum aparecer que muito (ou tudo) se faça por ela, já que ela não sabe fazer. E com isso a criança segue na posição passiva de fazer por si, sendo apontada por não fazer.

A esse respeito, Dolto (2005) nos convida a uma interessante reflexão com o que chama “tecnologia do saber-fazer" (Dolto, 2005, p.63).

Com a condição de que confiem nela, ensinem-lhe a tecnologia do saber-fazer, e façam-na compreender e integrar a realidade das coisas com as quais eles mesmos, na verdade, são

\footnotetext{
1 Todos os nomes de alunos aqui mencionados foram alterados na intenção de preservar a identidade da criança.
} 
confrontados, ensinando o porquê dos riscos e perigos. Com a condição de que, seja qual for o pequeno acidente que ela cause para si mesma em um momento em que o adulto tutelar não esteja presente, ela não tema falar-lhe a respeito, compreendendo que teve uma tecnologia ruim em relação ao que lhe fora dito e, a partir deste momento, ela tenha plena confiança no adulto, como um guia que merece crédito. $O$ adulto que explica para a criança que o perigo é o mesmo para si, caso tivesse feito o mesmo que ela, não humilha nem culpabiliza a criança. (Dolto, F, 2005, p.63)

Salienta-se, com isso, a fundamental importância da ação combinada que chancela, não só o aprendizado, mas também algo da transmissão da relação com a castração: de um lado a experiência vivida, de outro a linguagem que coloca em palavras esta experiência. Mais do que antecipar em palavras o perigo citado pela autora de se mexer com as tomadas de eletricidade, por exemplo, é transmitir algo que está para além do que se possa controlar ou evitar; a castração, como sabemos, inclui leis que estão para todos.

Dolto (2005) vem questionando o que se apresenta como excesso de segurança que o adulto busca dar à criança; o problema é que, muitas vezes, o que se faz na intenção de proteção, acaba por não dar à criança a sua própria experiência no mundo, rodeado de pequenas ameaças como o frio, uma tomada de eletricidade, ou mesmo o tropeço ao fazer uma corrida mais ousada. Não se trata de deixar a criança à própria sorte, mas sim, de dar a ela a orientação posta em palavras sobre o que possa acontecer, proporcionar, também, um espaço para que ela própria viva suas experiências, e, ainda, possa falar sobre elas depois.

Isso apareceu nos atendimentos em que os pais falam do quanto fazem pela criança no tangente ao escolar. Dar à criança subsídios para que ela tome para si as suas tarefas escolares a partir da sua implicação do seu papel de aluno é um dos objetivos ideiais do educador. É, no entanto, um processo que envolve muito mais do que uma demanda, pois coloca em cena a posição subjetiva de cada um naquela relação. Assim, a criança, por exemplo, vai dando notícias do complexo engendramento da sua posição frente ao desejo parental que lhe é atravessado; existe, ao que parece, um para além da exigência escolar nesta contingência de ensino remoto. Uma cartilha de roteiros de conduta e tarefas educativas não funcionam para todos os casos na sonhada tomada de responsabilidade pelos próprios afazeres, e esse desafio é lugar comum para o educador. Manter-se exclusivamente na lógica da consciência no campo educacional é deixar-se iludir pela prevalência do registro imaginário.

De modo geral, parece-nos que a criança vem ganhando uma posição igualitária em relação ao adulto, onde "mestres e discípulos são vistos como semelhantes, irmanados quase na mesma condição" (Pereira, 2008, p. 166). Como efeitos, vemos aumentar a fratura da autoridade dos pais e professores na atualidade, bem como verificar o desamparo de crianças que parecem estar à deriva de uma estruturação psíquica que lhe dê contornos e limites na relação com o outro, e na sua experiência de construção da própria segurança.

Outro caso sobre o que se apresenta como resistência da criança, também revela diferentes facetas. Os pais de Luís dizem que o problema central é a falta de interesse dele pelas atividades escolares. Isso, porém, vai ganhando outros nomes ao longo do atendimento. A família já havia organizado, junto ao menino, a sua rotina escolar - sempre após o almoço. Orientaram o filho quanto às ferramentas digitais, e com isso ele realizava e participava, praticamente sozinho, das propostas de atividades e aulas ao vivo. O olhar dos professores quanto à participação de Luís não se afinava com a questão da resistência ou falta de interesse trazida pelos pais.

A fim de situar com mais clareza de que modo, afinal, isso aparecia em casa, fui perguntando sobre as situações vividas no âmbito privado; o que se revela diz respeito a outras questões. Relatam o episódio em que, a partir de uma solicitação da professora para a gravação de um 
vídeo falando em inglês, Luís teria se negado, ficando muito nervoso, chorando e gritando. $\mathrm{O}$ que inicialmente veio como algo generalizado, já ganhara um recorte mais específico; apostando num contexto maior, quis saber melhor da relação dos pais com esse pedido da professora, então, aparece: a importância da língua inglesa para eles e o medo do possível bloqueio no filho para aprender uma língua estrangeira. Indícios, enfim, de uma certa cobrança desproporcional para a realização de uma atividade de rotina. O temor embolado com o ideal dos pais em relação à certo encaminhamento de aprender transformam um cenário de rotina num grande problema.

Outro episódio nomeado como dificuldade de viver a rotina escolar em casa, foi trazido pelos pais de Luís, que, segundo relatam, diante de pontuais quedas ou baixa conexão de internet costuma ter ataques de nervos, perder o controle e chorar aos berros. Isso foi também revelador de outras questões que nos tem chamado a atenção atualmente. Ainda neste mesmo atendimento, os pais contam que nos momentos livres Luís tem ficado horas à fio frente ao tablet alternando-se entre vídeos no YouTube e jogos de aplicativos. Esse ponto nos remete a um dos efeitos que a intoxicação eletrônica produz na relação do sujeito com o tempo, imprimindo aí uma urgência por respostas (Jerusalinsky, 2017, p. 26). Embora não seja o objeto deste trabalho, salientamos a importância de seguirmos atentos e refletindo sobre os efeitos que a intoxicação eletrônica tem sobre a estruturação subjetiva.

Outra família que buscou o serviço de orientação educacional sob a queixa de muita resistência para as tarefas escolares, é da aluna Paula. A mãe conta que desde o início das aulas online ela decidiu assumir toda a logística escolar da filha, excluindo-a, no entanto, da participação nas aulas ao vivo. Isso porque, segundo a mãe, na primeira experiência de interação nesses encontros virtuais, Paula ficou chorando, super irritada com todos falando ao mesmo tempo. A mãe conta que tentaram uma segunda vez, mas novamente foi muito difícil. Na fala livre da mãe, dispara que a filha é muito parecida com ela, que resiste às mudanças. A partir dos estranhamentos feitos, tendo em vista a hipótese de excessivo movimento de "proteção" que possa encobrir um certo embolamento entre mãe e filha, sugiro insistir na tentativa de participação nos encontros ao vivo - já que são momentos de troca e encontro com a escola. Apesar da visível resistência, a mãe se propõe experimentar, dizendo: tá, eu posso até tentar ver se ela fica. Nas semanas seguintes a aluna passou a participar das aulas ao vivo, sem a presença da mãe ao lado - já que estava trabalhando fora de casa - atuando de maneira participativa e descontraída das atividades propostas.

Foi possível escutar que esta mãe, como outras que trouxeram falas semelhantes, estava se desdobrando para acompanhar as atividades escolares da filha, mesmo que estressada e assoberbada com o trabalho e sua própria rotina. A tomada excessiva do controle sobre a rotina da filha, aparece como outro polo, mas não deixa de excluir a criança como sujeito do seu percurso escolar, da sua experiência na construção do seu papel de aluna. A mãe, sozinha, toma conta dos horários, imprime as tarefas, faz junto as atividades. A criança, nos parece passiva, como objeto de controle da mãe, que diz: agora eu é que sou a professora.

É comum que o orientador educacional deva lançar mão de encaminhamentos que, num primeiro momento, cause estranhamento nos pais; neste caso, notamos que era preciso uma certa separação entre mãe e filha para que a criança pudesse mostrar algo diferente do muito parecida com a mãe, e que sim, ela podia ficar parada em frente à tela participando das aulas. Mais do que o pedagógico, a importância psíquica da escola como lugar terceiro.

Um outro recorte de atendimento traz a seguinte motivação: temos enfrentado resistência e falta interesse do Manuel para acompanhar as aulas ao vivo. Relatam, ainda, a demasiada 
demanda de atenção dos pais que isso acarreta diariamente. Foi dito por eles que as aulas ao vivo costumam iniciar em clima de entusiasmo para o menino, mas nem sempre que Manuel pede para falar, lhe é dada a palavra, o que lhe gera muita frustração.

A fala vai fluindo, muitas coisas vão aparecendo: Manuel ganhou uma irmãzinha há poucos meses, e algumas vezes verbalizou para os pais que não pode mais ter atenção exclusiva deles, e que isso o deixa triste. Junto com a comparação da vida antes do nascimento da irmã, está a vida escolar podendo ser vivida na escola, antes da pandemia. Parece que este momento de confinamento e escola remota colocou Manuel para reviver questões que vão muito além de uma resistência ao virtual; em contrapartida, o menino arranjou um modo de tomar a presença dos pais, que ficam negociando com ele sua participação nas aulas.

Ali também aparece a culpa do pai pelo pouco tempo disponível para o filho; assim como o quão difícil é para ele, atualmente trabalhando em casa, ouvir do filho que, embora estejam todos em casa, não têm tempo para estarem juntos.

Isso é algo que aparece - implícita ou explicitamente - na fala de muitos pais que tiveram suas rotinas de trabalho levadas para dentro de casa junto com seus filhos. É quase unânime, neste público atendido, o discurso do aumento da demanda de trabalho em home office, e da frustração gerada por acreditarem que teriam maior qualidade de vida trabalhando de casa.

$\mathrm{Na}$ sequência, o pai fala da sua dificuldade em não se deixar tomar pelos argumentos do filho, e diz que chega a pensar em não o contrariar quando ele se nega em cumprir seu papel de aluno. É curioso ver, em tantos atendimentos realizados, o quão fragilizado parece o adulto parental em orientar a rotina do seu filho - seja ela escolar ou cotidiana, já que isso não parece ter estrita relação com a pandemia. Ao longo deste período em que a escola migrou para dentro de casa, isso veio apimentado pela seguinte fala: eu não estudei didática ou eu não sou professor (a). A questão, no entanto, não é a do ensino em si, daquilo que de fato se pudesse justificar pela falta de didática, mas sim, retrata uma certa falha no papel do adulto em sustentar, junto à criança, que ela passará a vivenciar a rotina escolar dentro de casa. Isso, afinal, vai além da vontade de um ou de outro envolvido, está para todos, é a contingência que nos foi imposta.

Em muitos dos atendimentos realizados, apareceu na fala dos pais o agradecimento - ou melhor seria dizer o alívio? - quando, ao representar um discurso institucional, foi salientada a importância de sustentar o papel de cada um naquela relação. Os pais, atualmente, parecem se ver numa posição de desautoridade frente aos seus filhos. Algumas famílias, inclusive, fizeram a solicitação para que eu, enquanto figura representante do discurso da escola, conversasse com os filhos a fim de reverter a situação de não estar sabendo lidar com a resistência destes com os estudos.

Foi comum, ainda, ouvir dos pais que a preocupação maior é com o bem estar emocional dos seus filhos. Em seguida, porém, fica o discurso da terrível sombra do não aprendizado, do medo da não alfabetização e acompanhamento dos conteúdos em tempos de escola online. Isso nos aponta para a lógica atual do discurso do campo educativo, onde o aluno precisa ter alto desempenho nas mais variadas competências.

Como dito anteriormente, as normativas educacionais brasileiras e os programas educativos oferecidos atualmente no mercado educacional aparecem pautados na responsabilização do indivíduo pelo viés psicologizante, portanto não incluem o sujeito do inconsciente - faltoso por constituição; tampouco consideram o mal-estar que atravessa as relações humanas. Assim, tais propostas tanto descartam o inconsciente como produtor de saber como exigem do eu um "saber-fazer" que seja autônomo e eficiente. 


\section{(In)concluindo}

A partir da análise das falas dos atendimentos realizados pela orientação educacional no período de ensino remoto, propusemo-nos a pontuar alguns efeitos e reflexões que um espaço de escuta pode produzir durante a pandemia de COVID-19. Ainda que de forma virtual, a busca pelo Serviço de Orientação Educacional aconteceu. Motivados pelo que, inicialmente, aparece como resistência da criança à rotina escolar em casa, tais atendimentos trouxeram pontos que nos são caros para pensar a parentalidade na atualidade.

Tendo a demanda dos pais como um norteador para delinear o que se espera como saber sobre a criança em idade escolar atualmente, notamos que tal demanda parece chegar com certa expectativa de uma resolução específica para a queixa apresentada. Quando uma mãe leva à escola uma reclamação sobre o filho que não está se enquadrando no que se espera dele, isso, em si, já diz algo da relação desse adulto parental com seu filho. Ao mesmo tempo, por se tratar de um assunto escolar em tempos de escola em casa, os pais primeiro buscaram a instituição, antes mesmo de procurarem implicar os filhos nesta contingência de escola remota - que está para todos e para cada um.

Houve, afinal, uma sondagem pela escola na intenção de se querer saber sobre a criança escolar, genérica, a quem o adulto parental não parece conhecer. Como se essa criança, a que parece precisar da escola para cumprir suas obrigações de aluno, demandasse um saber exclusivo do campo da educação sobre ela.

Sendo a escola um recorte do social, palco de importantes questões da atualidade de cada cultura, nos deparamos cotidianamente com os efeitos da relação entre o adulto e a criança. Se o orientador educacional é aquele que também toca na relação do adulto (neste artigo, o adulto paretal) no exercício do seu papel educativo, de que maneira este educador poderia atuar frente às questões inerentes ao processo educativo, senão posicionado em certo discurso?

Sobre isso, apontamos o viés psicologizante que o discurso educacional atual tem se firmado com a implementação da BNCC - Base Nacional Curricular Comum - e a oferta de programas educacionais. Os atendimentos realizados pela orientação educacional durante a pandemia, aqui recortados, corroboram com a percepção desta tendência psicologizante de certos posicionamentos subjetivos que se anunciam na relação adulto-criança na atualidade. Tendência essa que centraliza no indivíduo / no eu, o problema. A escuta pode ser oferecida, alguns apontamentos foram realizados, e vimos demandas sendo transformadas em questões; esta, afinal, é a proposta de uma orientação educacional que inclua a psicanálise.

Ainda assim, sabemos que a procura por um nome ou resposta para a representação ou solução de algo que não cessa de não se inscrever no sujeito, é uma lógica com a qual seguiremos lidando. Nos parece que essa busca pode estar cumprindo uma função de justificar alguma inadaptabilidade do eu ao meio externo. Assim, coloca-se uma das principais demandas do orientador educacional: orientar as famílias sobre o que fazer diante das queixas que trazem sobre os filhos - o que, muitas vezes, implica em desconstruir um pensamento psicologizante, incluindo as funções parentais e atravessamentos sociais naquilo que trazem nas suas falas.

O trabalho da orientação educacional com a psicanálise, ao admitir o sujeito do inconsciente, não se rende à oferta de uma simples equação entre educar e aprender, entre pedir e ser atendido; não acredita, afinal, que as relações operem num nível estritamente consciente, racional, cognitivo.

Ao tomarmos a queixa como um sinal de algo a mais da relação parental, abrindo um espaço de escuta para os pais que buscaram a orientação educacional, pudemos verificar efeitos e 
reflexões sendo transformados em questões que ultrapassam os desafios do ensino remoto. Apontam, afinal, para algo daquela relação adulto parental com seu filho. Dito de outro modo: Dito de outro modo: o ensino remoto, embora contingente, trouxe a tona questões que nos remetem à algo que parece se inscrever no âmbito estrutural da relação parental na atualidade.

Como vimos anteriormente, o orientador educacional é o profissional que - como o próprio termo sugere - é convocado a orientar aqueles com os quais se relaciona diretamente: alunos, professores, familiares. A demanda que se dirige a este educador, na maioria dos casos, é de oferecer uma orientação: algo que deva ser feito, um direcionamento a ser tomado diante de um problema. O orientador educacional lida com o fracasso das investidas educativas, com a repetição subjetiva no fracasso: o que chega a ele, é o sucesso do sintoma. Dar lugar para a escuta na instituição escolar, abre caminhos para que se veja para além do indivíduo - eu (supostamente) autônomo, idealmente autogerenciável; abre espaço para incluir outros elementos que estruturam todo um modus operandi, podendo-se pensar sobre isso.

Enquanto o psicanalista faz um manejo para que o sujeito, através da fala se apresente na transferência e possa ele próprio interrogar-se e construir suas próprias respostas sobre suas questões e implicação com o desejo, o orientador educacional pode oferecer as perguntas ao sujeito diante das questões que se evidenciam do seu (des)encontro com o outro - no caso, do adulto parental com seu filho.

Admitir o real do sintoma na instituição educacional nos parece um desafio necessário. Com isso, coloca-se em cena a questão do saber sobre o sujeito; de um lado uma instituição que possa se esvaziar desse lugar de saber prévio ou total sobre o aluno e suas apresentações sintomáticas, de outro o sujeito que possa se apresentar na sua singular articulação com a sua verdade, com o seu saber, e com a sua repetição - que vem por um sintoma.

\section{Referências}

Brasil. Ministério da Educação (2020). Base Nacional Comum Curricular: Educação é a base. Disponível em http://basenacionalcomum.mec.gov.br/images/BNCC_20dez_site.pdf.

Dolto, F. (2005). A causa das crianças (I. Storniolo \& Y. M. C. T. da Silva, trads.). Aparecida, SP: Ideias \& Letras.

Freitas, F. M.; Silva, J. A. da; \& Leite, M. C. L. (2018). Diretrizes invisíveis e regras distributivas nas políticas curriculares da nova BNCC. Currículo sem Fronteiras, 18, (3), 857-870 https://www.curriculosemfronteiras.org/vol18iss3articles/freitas-silva-leite.pdf

Freud, S. (1996). Prefácio a Juventude desorientada, de Aichhorn. In S. Freud, Edição standard das obras psicológicas completas de Sigmund Freud (J. Salomão, trad, Vol. XIX, pp.339343). Rio de Janeiro, RJ: Imago (Trabalho original publicado em 1925).

Grinspun, M. P. S. Z. (2011). A orientação educacional: conflito de paradigmas e alternativas para a escola. São Paulo, SP: Cortez.

Jerusalinsky, J. (2017). Que rede nos sustenta no balanço da web? - o sujeito na era das relações virtuais. In A. Baptistas \& J. Jerusalinsky (Orgs.), Intoxicações eletrônicas: o sujeito na era das relações digitais (pp. 13-38). Salvador, BA: Álgama.

Lacan, J. (2008). Do sujeito suposto saber, da díade primeira e do bem. In J. Lacan, $O$ seminário, livro 11: Os quatro conceitos fundamentais da psicanálise, 1964; texto estabelecido por Jacques-Alain Miller; [tradução M. D. Magno]. Rio de Janeiro, RJ: Zahar, 
Lacan, J. (1998). Duas notas sobre a criança. In J. Lacan, Escritos (V. Ribeiro, trad., pp. 369370). Rio de Janeiro: Zahar. (Trabalho original publicado em 1969).

Pereira, M. R. (2008) A impostura do mestre. Belo Horizonte, MG: Editora Argvmentvm.

Santiago, A. L. (2015). A dessuposição de saber na escola: aluno-problema e outras nomeações. In A. L Santiago \& R. M. de Assis, O que esse menino tem?: sobre alunos que não aprendem e a intervenção da psicanálise na escola (pp. 15-21). Belo Horizonte, MG: Editora Sintoma.

Voltolini, R. (2011). Educação e psicanálise. Rio de Janeiro, RJ: Zahar.

Voltolini, R. (2016). Prefácio a Crianças públicas, adultos privados. In: R. Voltolini (org.), Crianças públicas, adultos privados (pp. 7-12) - São Paulo, SP: Escuta / Fapesp.

Revisão gramatical: Ana Laura Berner

E-mail: anaberner@gmail.com

Recebido em novembro de 2020 - Aceito em abril de 2021. 